\title{
La querelle Mathiez-Aulard et les origines de la Société des études robespierristes
}

The Quarrel between Mathiez and Aulard and the Origins of the Société des

études robespierristes

James Friguglietti

\section{OpenEdition}

\section{Journals}

\section{Édition électronique}

URL : https://journals.openedition.org/ahrf/11113

DOI : 10.4000/ahrf.11113

ISSN : 1952-403X

Éditeur :

Armand Colin, Société des études robespierristes

Édition imprimée

Date de publication : 1 septembre 2008

Pagination : 63-94

ISBN : 978-2-200-92515-4

ISSN : 0003-4436

\section{Référence électronique}

James Friguglietti, «La querelle Mathiez-Aulard et les origines de la Société des études

robespierristes », Annales historiques de la Révolution française [En ligne], 353 | juillet-septembre 2008, mis en ligne le 01 septembre 2011, consulté le 01 juillet 2021. URL : http://journals.openedition.org/ ahrf/11113; DOI : https://doi.org/10.4000/ahrf.11113

Ce document a été généré automatiquement le 1 juillet 2021.

Tous droits réservés 


\title{
La querelle Mathiez-Aulard et les origines de la Société des études robespierristes
}

\author{
The Quarrel between Mathiez and Aulard and the Origins of the Société des \\ études robespierristes
}

James Friguglietti

1 Au début du vingtième siècle, François-Victor-Alphonse Aulard s'était affirmé comme le plus important historien de la Révolution française, non seulement en France, mais à travers tout le monde académique. Titulaire de la chaire d'histoire de la Révolution française à l'Université de Paris ${ }^{1}$, éditeur de la revue La Révolution française, auteur de nombreuses publications sur la période et rédacteur de plusieurs importantes collections de documents, notamment le Recueil des actes du Comité de Salut public, il domina ce champ d'étude d'une manière difficilement imaginable aujourd'hui. Comme l'un de ses meilleurs étudiants l'écrivit avec enthousiasme à son propos, en 1905 : « Si vous demandez à un intellectuel d'outre-Rhin, d'outre-Manche ou d'outre-Atlantique quels sont les historiens qui [...] honorent le plus la France à ses yeux et aux yeux de ses compatriotes [...], il citera certainement parmi les premiers celui d'Alphonse Aulard ». Ce même auteur continuait en remarquant « [que] M. Aulard est vraiment l'historien représentatif d'une époque, dont les ouvrages s'imposent au professeur, à l'érudit comme à l'homme du monde, à quiconque veut aborder l'étude de cette époque. [Il] personnifie en France l'histoire politique de la Révolution française. [Elle] est sa chose, son domaine. Personne n'y peut plus s'aventurer qu'à sa suite et comme en lui payant tribut ». Enfin, il ajoutait : « Mais M. Aulard ne s'impose pas seulement à l'attention du monde savant par ses publications et par la revue qu'il dirige : il est devenu, par son enseignement à la Sor-bonne, le chef d'une nombreuse et vivante école d'historiens qui travaillent sous sa direction. [...] C'est un maitre dans toute la force du terme ${ }^{2} »$. L'auteur de ce panégyrique était le jeune et prometteur historien Albert Mathiez. Aulard aurait difficilement pu imaginer que trois ans seulement après avoir fait cet éloge, Mathiez allait contester son autorité, remettre en question la validité de son 
œuvre, rabaisser son personnage et organiser à la fois une société et un périodique qui rivaliseraient avec les siens. Autrefois son étudiant reconnaissant et ami proche, Mathiez devint son opposant et critique. Cette querelle entre Mathiez et Aulard marqua une étape décisive dans l'historiographie moderne de la Révolution française. Elle fut à l'origine de la création de la Société des études robespierristes ainsi que de sa revue, les Annales historiques de la Révolution française, originellement Annales révolutionnaires, les deux fondées en 1907, et toujours très actives un siècle plus tard.

Cette rupture entre Mathiez et Aulard est aussi célèbre que ses causes et son déroulement demeurent obscurs. Il y a deux raisons pour cela. D'une part, Aulard ne daigna jamais répondre directement à son jeune rival du moment où la querelle éclata jusqu'à sa mort une vingtaine d'années plus tard. D'autre part, Mathiez, à une exception près ${ }^{3}$, n'énonça jamais clairement les motifs de sa rupture avec l'homme qui lui avait donné son amitié et qui avait tant fait pour avancer sa carrière entre 1900 et 1907. Toutefois, avec du recul, après un siècle et un nouvel examen de tous les documents existants, on peut avoir une meilleure compréhension de cette brouille regrettable qui, curieusement, refléta la lutte entre Danton et Robespierre pendant la Révolution elle-même. En effet les deux érudits ont inconsciemment rejoué la célèbre querelle qui divisa les deux dirigeants jacobins pendant la Terreur, sans qu'heureusement la guillotine ne détruise ni l'un ni l'autre.

Les protagonistes : Alphonse Aulard

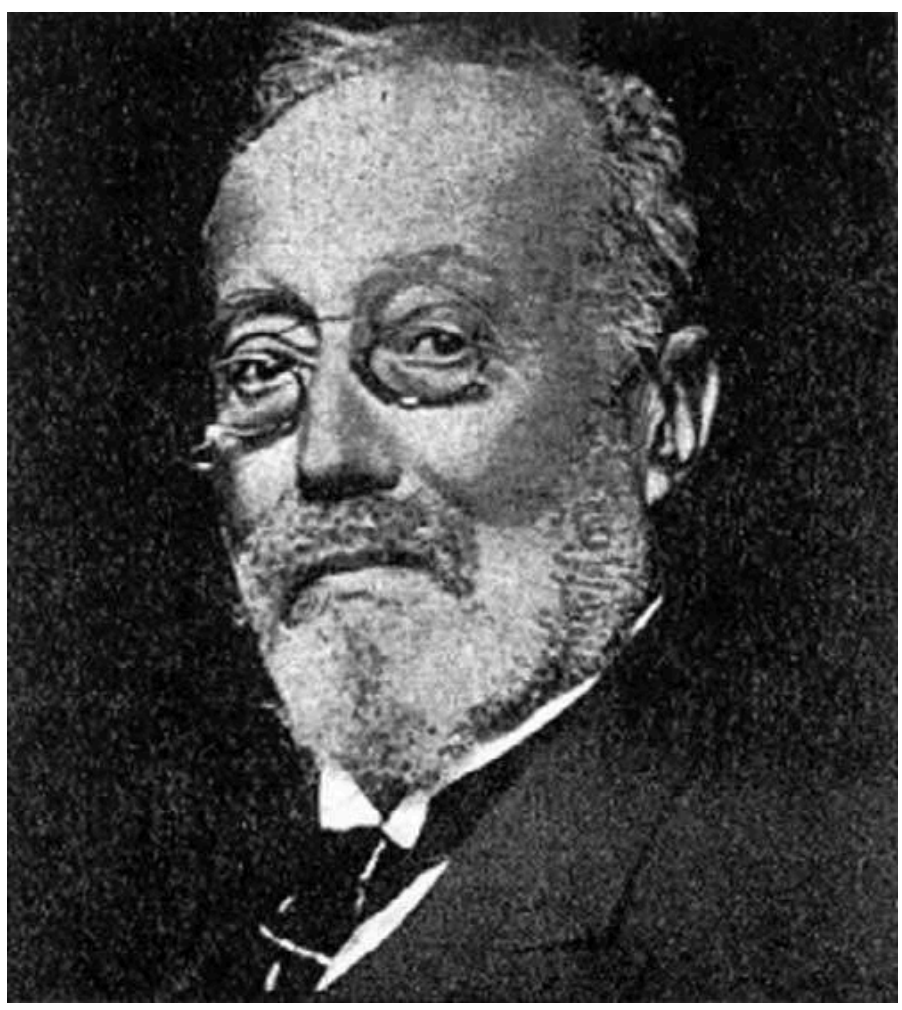




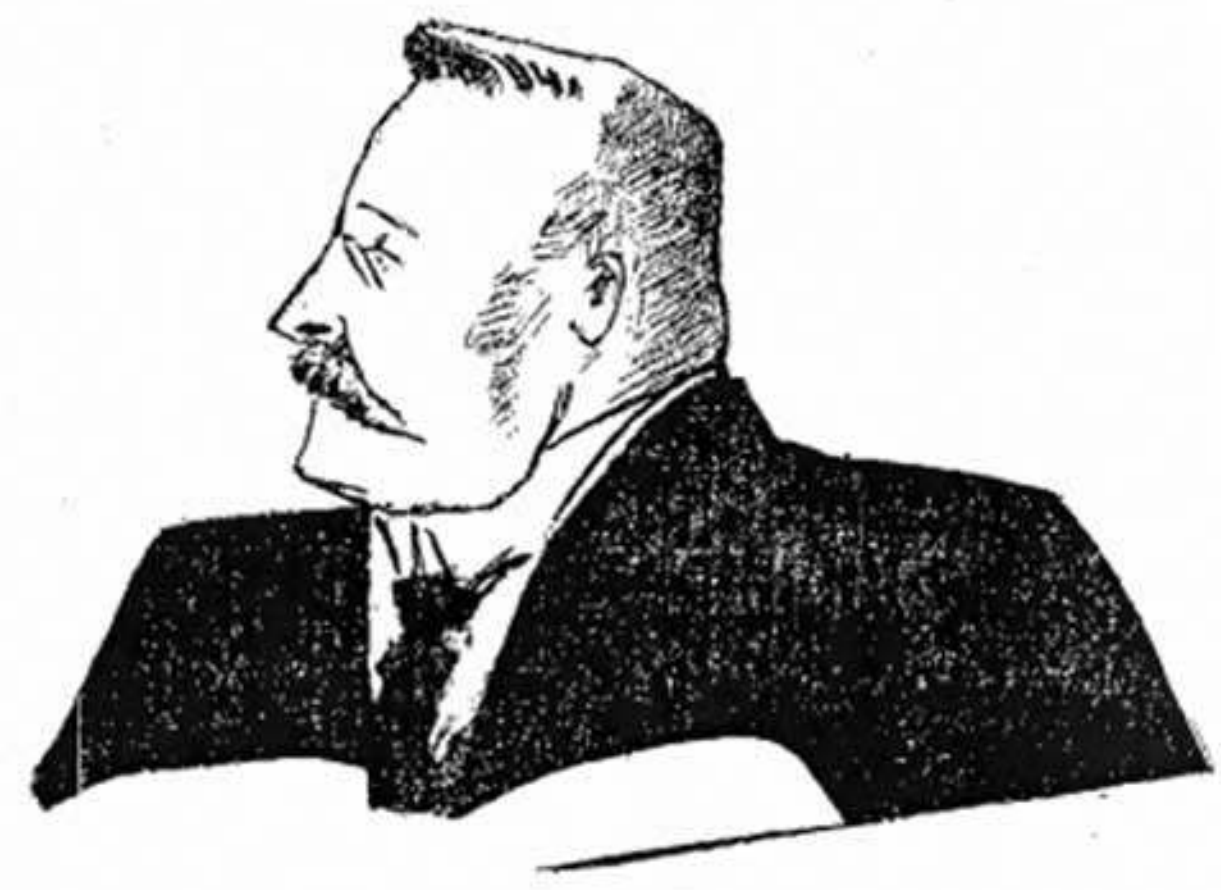

3 La querelle entre ces deux historiens de la Révolution s'est déroulée en trois étapes. Dans la première phase (1900-1907), Aulard et Mathiez étaient apparemment très proches à la fois intellectuellement et personnellement, travaillant ensemble pour avancer l'étude de la Révolution. Dans la seconde phase (1907-1908) une brèche s'ouvrit entre eux, qui fut d'abord privée et silencieuse, mais qui devint bientôt publique et amère. Dans la dernière phase (1909-1910), la division devint permanente quand Mathiez fulminait contre Aulard tandis que celui-ci continuait sereine-ment son travail, feignant de ne pas tenir compte de son rival. Chacun utilisa sa salle de classe, sa société et sa revue comme moyens de promouvoir la cause de son héros, Robespierre dans le cas de Mathiez, et Danton dans le cas d'Aulard. Aucun des deux ne réussit à détruire l'autre, mais l'amertume que leur dispute engendra divisa la communauté des universitaires français pendant une génération. Au début, Mathiez et Aulard semblaient entretenir une très bonne relation. Dans une lettre en date du 23 novembre 1930 adressée à son ami américain Louis Gottschalk, Mathiez évoquait ainsi ses premiers contacts avec son futur rival: "J'ai fait mes études à l'École normale supérieure où $\mathrm{M}$. Aulard n'enseignait pas et non à la Sorbonne où il occupait une chaire. Avant mon agrégation [1897], je n'avais jamais entendu un cours de M. Aulard. Ce qui est exact, c'est que, dans ces premières années, je lisais ses ouvrages avec ferveur. Après l'agrégation, je me mis en rapport avec lui pour lui proposer mes sujets de thèse : Les origines des cultes révolutionnaires; la Théophilanthropie et le culte décadaire ${ }^{4}$ ». Il négligea d'expliquer qu'après avoir quitté l'École normale supérieure, où il avait passé avec succès son agrégation en histoire et géographie, Mathiez étudia durant une année supplémentaire à l'Université de Lyon, puis accepta un poste au lycée Ingres à Montauban en 1898. La passion de Mathiez pour la Révolution et la Troisième République lui créa des problèmes considérables. De même que divers membres de la faculté, il dénonça un collègue, Guillaume-Tiburce Castex, catholique et conservateur, pour avoir loué le baron de Christiani qui avait frappé le Président de la République 
Gaston Loubet avec sa canne au champ de courses à Auteuil en juin 1899. Cette controverse devint vite publique, causa un scandale dans la ville et conduisit à une enquête menée par l'inspecteur d'académie. Après une investigation détaillée de l'affaire, Castex et Mathiez furent tous deux blâmés et mutés dans d'autres lycées. Dans son rapport, l'inspecteur concluait que « $\mathrm{M}$. Mathiez, impétueux, violent, vit dans une exaltation, passionné des choses de la politique, mais malgré tous ses talents de professeur, qui me paraissent remarquables, il est mal élevé $»^{5}$. Le recteur, Claude Perroud, était du même avis. Dans une lettre adressée au Ministre de l'Instruction publique, il observa que «[M. Mathiez] a commis une très mauvaise action, indigne d'un universitaire. J'en suis autant plus désolé qu'il s'agit d'un professeur de mérite; mais, même en tenant compte des circonstances atténuantes, telle que l'exaltation de son ardeur républicaine, l'emportement de la jeunesse et un manque d'éducation première, je ne puis que me faire à l'idée qu'une sanction est [...] nécessaire ici $^{6}{ }^{6}$.

Envoyé au lycée de Rochefort, Mathiez n'y passa qu'un semestre. Il eut la bonne fortune d'obtenir de la Fondation Thiers à Paris une bourse de trois ans avec pension complète et une allocation, ce qui lui permettait de travailler sans interruption à la préparation de ses thèses de doctorat. Pensionnaire à la Fondation, il se consacra entièrement à ses travaux de recherches. Peu de temps après son arrivée à Paris en 1900, Mathiez alla consulter Alphonse Aulard. Celui-ci eut sans aucun doute une longue conversation avec le jeune professeur à propos de sa passion pour la Révolution et donna son accord pour diriger ses thèses. Aulard, qui professait alors des cours à la Sorbonne sur l'histoire politique de la période, y compris des questions religieuses, encouragea certainement le jeune érudit à poursuivre des recherches sur deux mouvements religieux qui jusque-là n'avaient pas reçu beaucoup d'attention de la part des historiens : le culte décadaire et la Théophilanthropie. Il était sans doute déjà impressionné par l'érudition de Mathiez. Quelques mois auparavant, en juillet 1899, Claude Perroud, un ami proche d'Aulard et le même recteur qui avait demandé son renvoi de Montauban à la suite de l'affaire Castex, avait chaleureusement loué un article important de Mathiez: "Étude critique sur les journées des 5 et 6 octobre ", publié dans la prestigieuse Revue historique en 1898-18997 .

5 Selon Perroud, "cette étude, où les événements d'août et de septembre 1789 sont scrutés jour par jour avec une précision lumineuse, est un modèle de méthode et aboutit [...] à des conclusions qu'on peut regarder comme définitives $»^{8}$. Pendant qu'il se trouvait toujours à Montauban, Mathiez avait envoyé à Aulard une copie de cet article, signé avec la dédicace suivante : «À M. Aulard, au maître qui connaît le mieux l'histoire de la Révolution, je soumets timidement cette modeste étude de début " ${ }^{9}$. C'est sans doute pourquoi, quelques mois après sa publication, Aulard prit Mathiez sous son aile.

6 Les deux érudits semblaient avoir beaucoup en commun en plus de leur intérêt pour la Révolution. Ils étaient des provinciaux (Aulard est né en Charente, Mathiez dans le Doubs). Ils étaient normaliens (Aulard faisait partie de la promotion de 1867, Mathiez de celle de 1894). Plus important encore, ils étaient fortement républicains et anticléricaux, bien que l'historien aîné adhérait au radical-socialisme tandis que son élève appartenait au socialisme indépendant ${ }^{10}$. Comme Mathiez l'écrivit plus tard à son ami américain Gottschalk: «Tout de suite, il m'ouvrit La Révolution française, à laquelle je collaborai pendant mon séjour à la Fondation Thiers [...] et après. En ce temps-là, j'avais avec Aulard d'excellents rapports $»^{11}$. 
7 En effet, pendant les sept années qui suivirent, les deux hommes jouirent d'une relation très proche. En tant qu'éditeur de La Révolution française, Aulard ouvrit les pages de sa revue aux nombreuses publications de Mathiez, des articles aux comptes rendus. Presque tous traitaient des questions religieuses, puisque le jeune savant faisait des recherches pour ses thèses de doctorat. Début juillet 1900, Mathiez publia un long article sur «Les divisions du clergé réfractaire (1790-1802) » ${ }^{12}$ et une collection de documents sous le titre "Quelques lettres de Durand de Maillane $»^{13}$. Lors de l'Assemblée générale de la Société de la Révolution, tenue le 31 mars 1901, Mathiez eut l'honneur de présenter une courte communication à propos de Catherine Théot, publiée plus tard dans son intégralité dans la revue de la Société sous le titre: "Catherine Théot et le mysticisme chrétien révolutionnaire ${ }^{14}$. Aulard l'aida certainement à publier un article sur la Théophilanthropie dans la Grande Encyclopédie, qui résumait ses recherches sur le sujet et lui rapporta sans doute une rémunération ${ }^{15}$.

8 Tandis qu'il préparait ses thèses et des articles, il trouvait le temps d'assumer les fonctions de secrétaire général de la Société d'histoire moderne fondée en mai 1901 par Aulard ainsi que par d'autres historiens éminents : Émile Bourgeois, Arthur Chuquet, Antonin Debidour, Ernest Denis, Henri Hauser, Ernest Lavisse et Gabriel Monod. La première réunion de la Société eut lieu le 22 juillet sous la présidence de Monod. Ce fut Mathiez qui fit un discours définissant les objectifs et l'esprit du nouveau groupe. Et ce fut lui également qui devait répondre à toutes les demandes concernant les adhésions et les renseignements ${ }^{16}$. Il est remarquable qu'un si jeune universitaire - Mathiez n'avait alors que vingt-sept ans - puisse être choisi pour jouer un rôle aussi significatif. Ce choix attestait à la fois de son puissant intellect et de son énorme énergie. Le 23 mars 1904, Mathiez se présenta à la Sorbonne pour défendre ses thèses. Le jury, présidé par Alfred Croiset, doyen de la Faculté des lettres, réunissait Aulard, Ernest Denis, Henry Michel, Alfred Rambaud et Charles Seignobos. Des deux études présentées, sa thèse complémentaire, "Les origines des cultes révolutionnaires, 1789-1792 », était la plus originale et controversée. Mathiez y cherchait à expliquer les religions développées pendant la Révolution à travers les théories avancées par le sociologue Émile Durkheim. Incroyant et anticlérical, Mathiez accepta la proposition de Durkheim que les phénomènes religieux étaient déterminés non pas par leur contenu, mais plutôt par leur forme, c'est-à-dire les croyances exigées de la part de tous les membres d'un groupe et par l'exercice du culte. Tout en trouvant cette étude " très intéressante, très nourrie, très vive ", le jury considéra que Mathiez " avait un peu exagéré sa thèse en attribuant un caractère religieux à presque tous les actes collectifs des Français de 1789 à 1792 ». Ernest Denis exprima ses réserves quant à la nature du fait religieux. Mathiez s'emporta, déclarant que Denis avait tort. Une discussion violente s'ensuivit et Denis se leva pour quitter la salle. Mais Aulard intervint pour calmer les deux antagonistes et demanda à Mathiez de changer de ton ${ }^{17}$. Beaucoup plus tard, dans sa lettre à Gottschalk, Mathiez affirmait que sa brouille avec Aulard «a commencé lors de ma soutenance pour des raisons scientifiques. [Il] me reprocha d'avoir rejeté son opinion à lui que les cultes révolutionnaires étaient des expédients de défense révolutionnaire, alors que je soutenais que ces cultes se rattachaient à la pensée profonde des révolutionnaires sur le rôle de la religion dans la société ${ }^{18}{ }$. Mais Mathiez exagérait : c'était avec Denis et non avec son mentor qu'il se disputait.

9 La deuxième partie de la soutenance se déroula dans de meilleures conditions. La thèse principale, qui comportait 753 pages, ne dépassait pas les limites traditionnelles de 
l'analyse. Elle examinait l'histoire des cultes révolutionnaires, la Théophilanthropie et le culte décadaire et présentait un examen détaillé de ces religions civiques. Elle cherchait à démontrer que certains patriotes, déçus par l'échec de la Constitution civile, se tournèrent vers un nouveau mouvement spirituel pour effectuer un changement moral. Essentiellement déiste, la Théophilanthropie alliait une défense de la République à de fortes préoccupations morales et à des exercices du culte: elle instituait de simples cérémonies avec des hymnes et des sermons moralisateurs. Ces rites se déroulaient dans d'anciennes églises catholiques. Après des succès initiaux, dus à l'appui du Directoire, la Théophilanthropie perdit sa popularité quand le gouvernement l'associa au renouveau jacobin des dernières années du siècle. Tout en favorisant ce culte, le Directoire essaya de développer une religion officielle, le culte décadaire. Mais, malgré les meilleurs efforts du gouvernement, le culte décadaire ne parvint jamais à soulever l'enthousiasme général. Il déclina pour disparaître en même temps que le Directoire. Le coup d'État du dix-huit brumaire lui fut fatal.

Cette dissertation fut très favorablement accueillie par le jury. Aulard la loua comme «un exposé très neuf, très complet, très solide ». "Intéressant, décisif, impartial » ajouta-t-il, "ce récit est [...] un modèle d'exposition historique. Voilà un excellent travail, où la méthode est parfaitement appliquée ». Il se montra discret en concluant que son élève avait « fait preuve [...] d'un talent de parole très distingué, d'une force d'argumentation, d'une vigueur, plus émue dans la première séance, plus calme dans la seconde, mais toujours personnelle, originale $»^{19}$. Le jury décerna à Mathiez le titre de docteur ès-lettres avec la mention « très honorable ».

11 Mathiez prétendit dans sa lettre à Gottschalk que ses premiers différends avec Aulard remontaient à cette époque, mais cette allégation semble peu probable. Au contraire, il apparaît qu'il resta, du moins en apparence, fidèle à son patron et que les deux historiens de la Révolution entretinrent des liens d'amitié. Il faut remarquer que Mathiez avait dédicacé sa thèse principale à Aulard et à Émile Bourgeois, en ces termes : « Témoignage de reconnaissance et d'affection ». Qui plus est, il avait déclaré : "Je dois remercier ici en première ligne mon excellent maitre, M. Aulard $»^{20}$.

Son respect pour Aulard se manifesta également dans un article que Mathiez écrivit; "sur commande » devait-il protester en 1930. Publié dans la Revue des Charentes du 31 mars 1905, alors qu'Aulard envisageait de présenter sa candidature au Sénat dans son département natal, l'article de Mathiez louait chaleureusement l'homme et l'historien. Mathiez retraçait la carrière de celui-ci, en faisant l'éloge de son enseignement, ses recherches, ses publications. Il décrivait ses conférences comme "attachantes et nourries", marquées par "une érudition pénétrante et sagace, assaisonnée de bonhomie narquoise ». Aulard, continua-t-il, "a créé de toutes pièces l'histoire scientifique de la Révolution française. [...] avant lui [elle] était trop souvent la proie des hommes de parti qui y cherchaient matière à tirades éloquentes ou à conclusions passionnées. Elle est domaine tranquille de la science impartiale ». Mathiez félicitait son maître pour avoir appliqué une méthodologie exacte dans ses critiques de documents, pour avoir avancé des preuves, et pour avoir mis à jour un nombre extraordinaire de sources encore inconnues. Il louait également Aulard de la publication d'une vaste série de textes sur le Comité de Salut public, les Jacobins, ainsi que Paris sous la Réaction thermidorienne, le Directoire et le Consulat. "Ses disciples pourraient peut-être rectifier sur certains points ses conclusions, ce n'est qu'en se servant des instruments de travail qu'il a mis à leur disposition et en appliquant les 
méthodes qu'il leur a enseignées ", déclara-t-il. Enfin, il rendait hommage au travail journalistique d'Aulard, précisant que « par le tour piquant de la phrase et de la pensée, par la logique serrée du raisonnement, il égale les meilleurs polémistes ${ }^{21}$. Cet article était évidemment trop élogieux, et Mathiez regretta plus tard de l'avoir publié. Mais en 1905 l'amitié qui le liait à Aulard semblait être sincère et certainement avantageuse pour lui.

13 Écrivant à Gottschalk en 1930, Mathiez prétexta encore une autre source de friction avec Aulard. « Dans cette période, l'idée de rattacher le mouvement historique à la lutte des classes n'était pas chez moi une idée dominante », se souvenait-il. « Mais déjà [...] le combat social m'attirait comme le prouve ma conférence à la bourse du travail de Caen [en 1904] et ma prédilection pour Robespierre, considéré comme le plus social des révolutionnaires ${ }^{22}$. La conférence, intitulée «La question sociale pendant la Révolution française ", fut par la suite publiée in extenso dans la revue d'Aulard. On peut distinguer deux aspects intéressants de son article. Tout d'abord le nom de Robespierre n'est cité qu'une seule fois, lorsque Mathiez note simplement que «la chute de Robespierre [...] entraîna bientôt la chute de la Terreur $»^{23}$. La politique de l'Incorruptible n'est pas du tout discutée et ses relations avec les classes populaires sont totalement ignorées. Enfin, Mathiez tira la plupart de ses informations et de son inspiration d'Aulard, dont il cite l'article "Les origines historiques du socialisme français" fréquemment et favorablement ${ }^{24}$. Encore une fois, Mathiez montrait une loyauté totale envers son mentor et n'exprimait pas de sympathie pro-robespierriste, sentiment qui par la suite allait dominer sa pensée historique.

On trouve la preuve de l'amitié entre les deux historiens dans le bref compte rendu que fit Aulard d'un livre de Mathiez, Contributions à l'histoire religieuse de la Révolution française, paru en 1906. Le volume rassembla huit articles publiés dans La Révolution française et d'autres revues. Aulard le loua avec effusion, déclarant que «nos lecteurs connaissent l'érudition et la verve de ce chercheur, qui n'aime pas seulement les papiers inédits, mais aussi les idées. Son nouveau volume est plein de faits utiles, de remarques ingénieuses. J'en recommande vivement la lecture $»^{25}$. Pour sa part, Mathiez présenta à Aulard un exemplaire qui portait la dédicace : « À mon maitre M. Aulard, hommage d'affectueux respects $»^{26}$.

L'année suivante, Aulard ouvrit son journal à une série d'articles écrits par Mathiez et intitulés «La France et Rome sous la Constituante d'après la correspondance du cardinal Bernis ", dont les six parties parurent entre 1907 et $1908^{27}$. Mais tandis que les relations entre les deux érudits apparaissaient excellentes, leur brouille se préparait dans les pages de cette même revue. Ironiquement, ce fut une attaque dirigée par Aulard contre l'historien conservateur Hippolyte Taine qui fut à son origine. À l'automne 1905, Aulard avait institué un cours public à la Sorbonne sur "Taine historien de la Révolution française ». Ce qui rendait le cours inhabituel était la minutie et l'implacabilité avec lesquelles il assaillait le texte et l'érudition des Origines de la France contemporaine. Passer deux années à chercher à démolir cet ouvrage qui avait eu de nombreuses éditions et qui était largement estimé semble extraordinaire et même excessif. Aulard publiait ses conférences sur Taine en dix parties dans La Révolution française à partir de mars 1906 jusqu'en septembre 1907. Ces articles furent réunis en un seul volume, avec corrections et additions, en sus d'un chapitre final, à la fin de $1907^{28}$.

Dans la préface à son étude, Aulard affirmait que «nous sommes [...] assez éloignés, dans le temps, et de l'homme et de l'œuvre, pour les juger sans passion ». «Je n'ai point 
de préjugé contre Taine", continuait-il. "J'ai plutôt en sa faveur un préjugé d'adolescence, du temps où j'étais élève à l'École normale [et] je l'écoutais, avec un respect sympathique, à son cours de l'École des Beaux-Arts ${ }^{29}$. Étant donné qu'Aulard allait consacrer 330 pages à une réfutation totale des Origines de la France contemporaine, ces commentaires semblent ou naïfs ou hypocrites. En 1884, Aulard avait déjà publié un compte rendu critique du premier volume de l'ouvrage de Taine dans La Justice, le journal de Georges Clemenceau ${ }^{30}$. En 1903, quand le conseil municipal de Vouziers (Ardennes), commune natale de Taine, avait voté en faveur de l'érection d'un monument à sa mémoire, Aulard avait dénoncé le projet: "Taine n'est pas un historien : c'est un pamphlétaire, un pamphlétaire de droite. Qu'on le statufie, si on veut. Mais que ce soient les gens de droite, et surtout l'Église catholique, qui souscrivent à sa statue ${ }^{31} »$. Dans son cours à la Sorbonne, Aulard espérait certainement qu'en détaillant les innombrables erreurs que Taine avait commises, il avait effectivement détruit sa réputation en tant qu'historien. À peu près au même moment, l'étudiant favori d'Aulard donnait une conférence sur Taine à l'École des hautes études sociales. Pourtant, Mathiez considérait l'auteur des Origines de la France contemporaine d'un point de vue complètement différent. Contrairement à la méthode adoptée par son maitre, Mathiez ne disséqua pas l'ouvrage page par page. Il exprima une attitude beaucoup plus modérée. Pour lui, Taine était moins un historien qu'un philosophe et un homme de lettres qui avait commencé à écrire l'histoire à une étape avancée de sa carrière. Son but, selon Mathiez, était de découvrir le mode de gouvernement le mieux adapté à la France, à travers un examen de l'histoire du pays. Son conservatisme politique et sa méfiance à l'égard du peuple étaient déjà bien enracinés en lui bien avant la composition de son volume sur la Révolution, dont il avait condamné les principes. Selon Mathiez, Taine croyait que l'autorité de n'importe quel gouvernement devait reposer sur la tradition et la propriété. Taine fondait ses théories a priori, cherchant d'abord les lois générales de l'histoire, puis disposant les faits pour les étayer. Pour Mathiez, la sociologie historique exposée dans Les origines de la France contemporaine n'était ni historique ni sociologique, car les groupes de faits étaient étudiés indépendamment des circonstances accidentelles, méthode fausse et mal appliquée, de nature anti-scientifique. L'ouvrage de Taine était essentiellement « un plaidoyer ou un pamphlet" plein de "violences déclamatoires ", d'« épithètes injurieuses » et de « métaphores brillantes $»^{32}$.

17 Si Mathiez se montra plus perspicace qu'Aulard envers Taine et ses méthodes, il ne répudia pas toutefois l'étude d'Aulard. Il déclara plutôt qu'Aulard avait donné « le coup de grâce à la réputation de scientifique de Taine ». Mathiez ajoutait qu'« il a eu le courage et la patience, dont il ne peut être trop loué, de vérifier une à une chacune [de ses] affirmations [...]. Le gigantesque erratum qu'il est en train de dresser et qu'il accroît sans cesse est dans sa précision un éloquent réquisitoire ${ }^{33} »$. Mais tout en félicitant son maître, Mathiez démontrait une bien meilleure compréhension de Taine, car il analysait sa philosophie ainsi que ses méthodes d'une façon plus objective et compréhensive ${ }^{34}$.

18 Il est singulier que les deux historiens, qui s'accordaient pour constater que l'érudition de Taine était médiocre et son œuvre insuffisante, devaient bientôt se brouiller à l'égard de la critique acerbe qu'Aulard fit des Origines de la France contemporaine. Le vieil historien ne prévoyait pas que son élève lui chercherait querelle à propos d'une question aussi invraisemblable. Il ne soupçonnait guère que l'esprit d'indépendance ainsi que le tempérament violent et rancunier de Mathiez allaient se déchaîner bientôt 
et rompre leur amitié. Mathiez ne voulait plus rester un apprenti ; il espérait devenir son propre maître. En 1907, alors que les deux érudits semblaient travailler étroitement ensemble, les désaccords entre eux, tant professionnels que personnels, commencèrent à se révéler ouvertement. Dans sa lettre à Gottschalk, écrite en 1930, Mathiez ne fournit pas d'explication solide des raisons pour lesquelles la querelle commença à ce momentlà et se développa comme elle le fit. Aulard, pour sa part, ne daigna jamais en parler en public $^{35}$.

19 Ce qui n'était pas prévisible à l'époque peut être compris aujourd'hui si l'on examine attentivement les écrits de Mathiez et si on observe comment il s'émancipait graduellement de l'influence d'Aulard, même s'il semblait rester son fidèle élève et disciple. C'était bien Mathiez qui initia la querelle et la poursuivit pendant quelques vingt ans. Elle reflétait leur désaccord sur les rôles historiques des deux grandes figures de la Révolution: Danton et Robespierre. Dans son Danton et la paix (1919), Mathiez rappelait : «Au sortir de l'École normale [1897] j'étais nourri de la légende, je croyais au généreux Danton assassiné traîtreusement par l'ambitieux Robespierre, je n'avais contre l'histoire officielle aucun parti pris. J'étais contre elle sans défense ${ }^{36} »$. C'était son maître Aulard qui incarnait cette « histoire officielle». Le vieil universitaire avait certainement exprimé depuis longtemps son hostilité acharnée envers Robespierre ainsi que son grand enthousiasme envers Danton. Dans son article « Aux apologistes de Robespierre ", publié dans le premier volume de ses Études et leçons, Aulard déclarait: "Je maintiens qu'[il] assassina traîtreusement, et sans circonstances atténuantes, avec la plus froide préméditation, l'homme qui soutenait une politique laïque et française par opposition à un système presque théocratique, son frère d'armes, son camarade magnanime, le bon et le grand Danton $[. . .]^{37}$ ».

Lorsque Mathiez commença à travailler sous la direction d'Aulard en 1900, il connaissait certainement les opinions de son maître. Mathiez se souvint ainsi de ses premiers doutes: «Les doutes commencèrent quand je me mis à étudier pour mes thèses de doctorat les cultes révolutionnaires. Il me parut que le rôle de Robespierre dans l'élaboration de cette entreprise politico-religieuse avait été dénaturé et qu'il n'était pas le pontife qu'on prétendait. Je crus découvrir dans la déchristianisation, qu'il combattit, une surenchère démagogique dirigée contre le Comité de Salut public par un groupe de députés d'affaires dont les friponneries étaient sur le point d'être

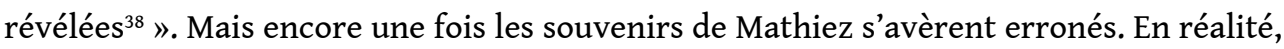
Mathiez n'avait rien écrit ni sur Robespierre ni sur Danton avant 1901. L'étude qu'il publia cette année sur Catherine Théot contient même quelques allusions légèrement défavorables à Robespierre ${ }^{39}$. Mais six ans plus tard, il modifia le texte avant de le publier dans ses Contributions à l'histoire religieuse de la Révolution française. Mathiez présentait alors les idées de Robespierre sous un jour beaucoup plus sympathique. Il alla jusqu'à porter un défi aux idées d'Aulard, mais sans violence, se montrant même conciliant à l'égard de son maître. Pendant l'intervalle, Mathiez avait considérablement modifié son opinion sur Robespierre. Pourtant, il restait conciliant envers son vieux maître. Dans une note apposée à un paragraphe sur l'institution des fêtes nationales par Robespierre le 18 floréal an II, Mathiez ajouta : «M. Aulard a lui-même remarqué que les fêtes instituées par Robespierre sont empruntées à un rapport antérieur présenté par le conventionnel Mathieu $»^{40}$. Il cita également comme sources plusieurs ouvrages d'Aulard, dont son Histoire politique de la Révolution française. 
21 Au cours de ces années, il est évident que Mathiez s'éloignait peu à peu des opinions de son mentor et devenait de plus en plus favorable envers l'Incorruptible. Comment peuton expliquer cette évolution? Il semble que Mathiez ait commencé à changer d'opinion sur Robespierre quand ses recherches aux archives et sa méfiance croissante à l'égard d'Aulard le convainquirent que Robespierre avait été diffamé par les historiens positivistes. L'Histoire socialiste de Jean Jaurès aida sans aucun doute à transformer ses opinions. Dans un compte rendu des quatre volumes que Jaurès avait publiés entre 1901 et 1904, Mathiez se montrait impressionné par l'admiration que le député socialiste éprouvait pour le conventionnel jacobin. «Je n'ai compris qu'à la suite de M. Jaurès la politique de Robespierre et du Comité de Salut public à l'égard des dantonistes et des hébertistes", écrivit-il. "Si du simple exposé des faits, Danton sort quelque peu diminué et Robespierre grandi, la vérité seule y gagnera $»^{41}$. Rappelons-nous aussi que dans son volume sur la Convention, Jaurès fit ce célèbre commentaire : "Je suis avec Robespierre, et c'est à côté de lui que je vais m'asseoir aux Jacobins ${ }^{42}$.

En plus des écrits historiques de Jaurès, grande était l'influence du député socialiste Gustave Rouanet. Il est probable que Mathiez lut la Revue socialiste qu'il éditait entre 1898 et 1904. Héritier d'une forte tradition socialiste révolutionnaire, Rouanet avait vraisemblablement encouragé le jeune historien à se détacher des vues historiques d'Aulard pour se rapprocher de l'Incorruptible. Après la création des Annales révolutionnaires en 1908, Rouanet donna fréquemment sa collaboration à la revue ${ }^{43}$. Comme Mathiez allait écrire en 1923 : «Quand j'essayai [...] de développer notre Société historique, je ne me heurtai nulle part à plus de préventions stupides que dans les milieux socialistes. Gustave Rouanet fut un des rares membres du parti, avec Albert Thomas, à m'apporter un concours empressé et dévoué ${ }^{44} »$.

23 À ces influences positives, une autre influence, celle-ci négative et peut-être la plus importante, doit être ajoutée. Ironiquement, il s'agissait de son patron influent, son prétendu ami Aulard. Pendant les sept années durant lesquelles il travailla avec lui, Mathiez devint de plus en plus dédaigneux de l'ardeur que le vieil érudit montrait pour Danton. Alors qu'il commençait à admirer et à s'identifier avec l'incorruptible Robespierre, Mathiez commença à croire qu'Aulard ressemblait au député corrompu qu'il admirait. Étant donné l'absence de documentation, les étapes de l'évolution de Mathiez ne peuvent pas être retracées avec grande précision. Mais certains de ses traits psychologiques fournissent des indicateurs utiles.

Tout d'abord, il y avait la différence d'âge considérable entre Aulard et Mathiez. Aulard naquit en 1849 alors que son rival naquit vingt-cinq ans plus tard. Au début, cela a pu paraître sans grande importance. Quand ils se rencontrèrent pour la première fois, ils se lièrent grâce à leurs études à l'École normale supérieure ainsi qu'à leur enthousiasme mutuel pour l'histoire de la Révolution. L'esprit brillant et l'énergie du jeune érudit avaient aussi sans aucun doute poussé Aulard à voir en lui un digne élève et disciple. Cependant, des origines sociales et des tempéraments distincts ne tardèrent à creuser un fossé entre eux. Aulard, bien que provincial comme Mathiez, était fils d'un professeur de philosophie et inspecteur d'académie. Mathiez, en revanche, était fils d'un aubergiste modeste. Les attitudes condescendantes de son patron ont dû beaucoup déplaire au jeune historien. En plus, Aulard était un républicain de longue date qui avait vu naître la Troisième République en 1870 et qui participa vaillamment à la Guerre de 1870-1871. Il admira Léon Gambetta comme homme d'État et orateur, ce qui avait dû l'amener à étudier les orateurs de la Première République (sa première 
entreprise dans le domaine de l'histoire de la Révolution traitait de ces "ténors " révolutionnaires $)^{45}$. Radical dès sa jeunesse, libre penseur et anticlérical, Aulard était très en vue dans les cercles radicaux-socialistes et contribua régulièrement au journal de Georges Clemenceau La Justice à partir de 1884. Très voltairien, il affichait une attitude digne et sereine, mais il était imbu de lui-même. Aulard semblait prendre plaisir à acquérir des postes et des titres qui lui donnaient à la fois du pouvoir et de l'influence, particulièrement dans le monde académique. De plus, Mathiez, universitaire très sérieux et productif qui consacrait son temps à faire des recherches dans les archives, trouvait que l'érudition d'Aulard était plutôt médiocre. Contrairement à Aulard, qui avait débuté comme spécialiste en littérature et qui avait écrit sa thèse de doctorat sur le poète italien Giacomo Leopardi, Mathiez avait été formé à la méthode «scientifique " à l'École normale supérieure une génération après Aulard, alors que le niveau des études s'était considérablement élevé.

À un moment donné dans ses recherches, Mathiez découvrit que les collections de documents qu'Aulard publiait, en particulier le Recueil des actes du Comité de Salut public, étaient loin d'être parfaites, et qu'une grande partie du travail n'avait pas été effectuée par Aulard lui-même, mais par des assistants subventionnés par l'État. Ce n'est qu'après avoir rompu avec Aulard en 1908 qu'il put exprimer son mépris pour Aulard en tant qu'historien. Aussi longtemps qu'il fut son élève, il se contenta de faire des allusions à ses ouvrages qu'il considérait imparfaits. Alors qu'en 1904 il remarquait, à propos d'une collection de documents, que "le texte publié par M. Aulard [...] offre quelques variantes $»^{46}$, il pouvait déclarer quatre ans plus tard qu'il avait « constaté [...] que les scribes de M. Aulard ne se reportaient pas toujours aux minutes, n'indiquant pas les variantes $»^{47}$.

En 1907-1908, Mathiez devait considérer Aulard vieillissant avec moins d'affection. Fier, ambitieux et impatient, il devint moins tolérant à l'égard de son patron à mesure qu'il s'affirmait dans son métier d'historien. Dans leurs relations personnelles avant 1907, Mathiez ne pouvait donner libre cours à sa rancune. Après tout, Aulard avait été très généreux, lui ouvrant les pages de La Révolution française, promouvant ses publications, le présentant à d'importants historiens, et l'aidant à faire avancer sa carrière académique. C'est seulement après leur rupture en 1908 que tous ces ressentiments éclatèrent bruyamment et publiquement. Mathiez allait poursuivre Aulard implacablement jusqu'à sa mort en octobre 1928.

Les sentiments personnels de Mathiez sont étroitement liés à ses découvertes historiques. Il vint à la conclusion que son maître partageait l'opportunisme et la vénalité de son héros Danton, alors que lui-même s'assimilait à l'honnête et courageux Robespierre. Alors qu'il faisait des recherches sur la Révolution, surtout sur la période de la Terreur, Mathiez devint de plus en plus soupçonneux de l'honnêteté, de la moralité et du patriotisme de Danton, de même qu'il trouva encore plus de raisons de célébrer l'intégrité, la générosité et les qualités de chef de Robespierre. Si Danton était tellement malhonnête, son champion devait l'être aussi. Dans son esprit, Danton et Aulard fusionnèrent en une seule et même personnalité. Et en tant que socialiste, Mathiez s'éloigna progressivement du radical-socialiste Aulard, dont l'ami Clemenceau était le président du Conseil de 1906 à 1909.

En 1930, Mathiez expliqua à son ami américain Gottschalk qu'il avait fini par mépriser «la politique de défense républicaine d'Aulard et de ses amis radicaux, qui, systématiquement, ne voulaient pas attirer l'attention sur le rôle primordial de la 
bourgeoisie et sur la misère du peuple qui a joué le rôle de dupe ». Il ajouta qu'il avait "quitté de bonne heure les thèses apologétiques du maître, dès que je me suis aperçu où elles menaient $\aleph^{48}$. Un fait au moins est certain : en 1907, Mathiez était disposé à porter un défi à l'autorité de son maître en collaborant à la création d'une société historique rivale et en fondant une revue concurrente qui seraient consacrées à la bête noire d'Aulard, Robespierre.

En 1907, une Société des études robespierristes était fondée par un groupe de savants et hommes politiques. La première annonce de cette fondation parut dans le numéro de la Revue critique d'histoire et de littérature du 9 décembre 1907. Cette même annonce déclarait que sa revue, les Annales révolutionnaires, serait une publication trimestrielle, paraissant tous les trois mois par fascicules de 160 pages in- $8^{49}$. Arthur Chuquet, directeur de la revue, en fut le principal responsable, et le siège social fut établi dans son immeuble, à la librairie Ernest Leroux, 28, rue Bonaparte, Paris VI ${ }^{\mathrm{e}}$. Chuquet, auteur de nombreuses études sur l'histoire militaire de la Révolution, ne semble pas avoir été un robespierriste actif avant cette date. Parmi les autres responsables de la nouvelle société on peut citer : Georges Renard, ancien communard, professeur de sociologie au Collège de France et rédacteur de la revue La Révolution de 1848 ; Ferdinand Buisson, député et l'un des dirigeants de la Ligue des droits de l'homme; Célestin Bouglé, professeur de philosophie sociale à l'Université de Toulouse ; Édouard Herriot, maire de Lyon depuis 1905, qui avait obtenu son doctorat en présentant une thèse sur Madame Récamier ; Jean-Bernard Passerieu, journaliste et écrivain spécialiste de la Révolution ; Louise Lévi, écrivain, qui en 1904 avait traduit de l'allemand une biographie de Robespierre écrite par Karl Brunneman ; Jacques Duplay, médecin et descendant de la famille chez qui Robespierre avait logé pendant ses dernières années; Paul Coutant-Le Bas (Stéphane Pol), biographe de Lebas, le conventionnel ancêtre de sa femme; Hippolyte Buffenoir, journaliste, iconographe de Rousseau, éditeur des œuvres de Saint-Just ; Victor Barbier, historien d'Arras ; ainsi que quelques historiens étrangers dont Ludo Hartmann, fils d'un révolutionnaire allemand de 1848, alors privat-docent à l'Université de Vienne; Otto Karmin, historien suisse de la Révolution; Friedrich Kircheisen, biographe allemand de Napoléon; et le savant américain John Boyd Thacher.

Toutefois, le principal responsable de la fondation de la Société fut Charles Vellay, qui en devint le secrétaire provisoire. Né à Vienne (Isère) en 1876, fils d'un tapissier, Vellay avait obtenu son doctorat à l'Université de Grenoble en 1904. Sa thèse traitait du culte et des fêtes d'Adonis-Thammouz dans l'Orient antique. Bien qu'il ait consacré la plus grande partie de sa vie à étudier la Grèce antique, Vellay montra très tôt un fort intérêt pour la Révolution française, et plus spécialement pour la vie de Saint-Just. En 1906, après une visite à Blérancourt pour voir la maison de Saint-Just, il publia un article intitulé «Saint-Just, premières luttes politiques (1790-1792) " ${ }^{50}$. L'année suivante, il en écrivit un second: "Les poursuites contre Organt " $^{51}$. Il couronna son travail sur le Conventionnel avec une édition en deux volumes des Euvres complètes de Saint-Just parus en 1908.

31 La fascination de Vellay pour la vie de Saint-Just explique peut-être pourquoi il chercha à établir un groupe favorable à son collègue Robespierre. Malheureusement, les détails précis de la création de la Société des études robespierristes restent inconnus. Lors de sa première Assemblée générale, tenue le 29 novembre 1908, Vellay expliquait que « les fondateurs de la Société avaient [...] été frappés de ce fait, que, depuis un certain 
nombre d'années, il règne dans l'histoire de la Révolution une sorte d'antirobespierrisme systématique [...], une tendance à nier ou à rabaisser le rôle historique de Robespierre, à dénaturer sa pensée et ses doctrines, à renouveler contre lui la campagne d'injures qui suivit le 9 thermidor ». Il ajouta qu'il était temps d'établir « une étude méthodique et raisonnée de celui qui fut un des plus grands acteurs de la Révolution, et dont la mort ouvrit l'ère des réactions politiques et des réactions sociales $»^{52}$.

Dans le numéro du 9 décembre 1907 de la Revue critique d'histoire et de littérature, les objectifs de la nouvelle association furent exposés : «[Elle] a pour but de publier tous les documents historiques qui peuvent apporter, dans la biographie de Robespierre, dans l'étude de ses idées politiques, dans l'histoire de son influence, une nouvelle clarté. Elle se propose de travailler par les méthodes les plus rigoureuses et les plus précises, dans une impartialité absolue l'analyse d'une époque qui, défigurée par la passion, demeure encore, sur bien des points, mal étudiée, mal connue, mal jugée. Si elle considère Robespierre comme celui qui, depuis l'ouverture des États généraux jusqu'au 9 thermidor, incarne le plus parfaitement la Révolution elle-même, elle étend par une conséquence naturelle, le champ de ses investigations jusqu'à la Révolution toute entière, et jusqu'aux manifestations qui au cours du XIX ${ }^{e}$ siècle, ont marqué le développement et l'histoire de la pensée révolutionnaire ${ }^{53}$ ».

Ce manifeste ne présentait aucune hostilité envers la Société de la Révolution d'Aulard. Toutefois, La Révolution française garda le silence total à l'égard du nouveau groupe. Cette même annonce déclarait que la Société des études robespierristes allait lancer deux projets : l'un était l'institution d'une revue, les Annales révolutionnaires : «[Elles] publient, dans chaque numéro, des études originales, des documents inédits, une bibliographie de tous les ouvrages relatifs à l'histoire de la Révolution, et une analyse des revues françaises et étrangères ». Mais c'est seulement le 9 avril 1908 que la Revue critique d'histoire et de littérature annonça la parution du premier numéro des Annales révolutionnaires et fournit une table détaillée de son contenu. Il paraissait sous les auspices de la Librairie Ernest Leroux, la même maison qui éditait la Revue critique d'histoire et de littérature. Il est assez surprenant que la fondation de la Société des études robespierristes ne causât pas d'hostilité immédiate entre Aulard et Mathiez. En fait, celui-ci continua à publier dans La Révolution française une longue série d'articles intitulée «La France et Rome sous la Constituante d'après la correspondance du cardinal Bernis ». La série avait commencé à paraître dans le numéro de février 1907 ; la sixième et dernière partie parut en avril 1908, avec la mention « à suivre " ${ }^{54}$.

Le premier numéro des Annales révolutionnaires, un fascicule de 183 pages, présentait des articles de Chuquet, Barbier, Lévi, Vellay et Mathiez, consacrés en grande partie à Robespierre. Le numéro incluait également des documents inédits sur la période révolutionnaire, des comptes rendus et une revue de presse qui présentait une analyse du dernier numéro de La Révolution française. Bien que la plus grande partie du numéro soit consacrée à l'Incorruptible, la revue ne contenait rien qui pût inquiéter Aulard. Mais une nouvelle société et une nouvelle publication traitant de la Révolution sous un angle favorable à Robespierre constituaient une rivalité qui ne pouvait plaire au dantoniste Aulard. Il fit semblant d'ignorer leur existence. En dépit de leur importance, les Annales révolutionnaires n'étaient pas citées dans sa revue. Toutefois, les relations entre Mathiez et son ancien patron paraissaient rester étroites. Pourtant une crise devait bientôt se produire. En mars 1908, Mathiez trouva des raisons de dispute avec 
des amis d'Aulard, ce qui entraîna rapidement une controverse avec Aulard lui-même. La querelle débuta au sein de la Société d'histoire moderne, à la fondation de laquelle il avait participé en 1901. Ce mois-là Mathiez avait tenté de rendre publiques les subventions distribuées à des membres de la Société pour différentes publications, et de s'assurer que ces subventions étaient confiées à des personnes détermi-nées ${ }^{55}$. Il devait expliquer quelques mois plus tard qu'il avait présenté cette motion parce qu'il se méfiait de la gestion financière de Pierre Caron, rédacteur de la Revue d'histoire moderne et contemporaine et de nombreuses autres publications financées par la Société : "Toutes les subventions dont dispose la Société d'histoire moderne sont allées comme les fleuves dans la mer aux différentes entreprises qu'a fondées $M$. Pierre Caron et à elles seules [...] à n'importe quel moment, [il] demande 200, 300 fr., la somme est accordée sur le champ sans condition. Pas de rapport, pas de formalité d'aucune sorte ». Mathiez avait déjà manifesté sa colère à l'assemblée de décembre 1907, au cours de laquelle on avait accordé 1500 francs à Caron. Croyant que Caron jouait trop librement avec les fonds de la Société qui n'avait sur lui aucun contrôle, il souleva le problème de nouveau à l'assemblée d'avril. Il présenta une motion qui suggérait qu'un rapport écrit devrait accompagner toute demande de subvention. La motion fut acceptée, mais Mathiez ne reçut pas satisfaction parce que Caron continua à recevoir des fonds et à contrôler tous les manuscrits soumis à la Société pour leur publication. «Il reçoit tout seul le manuscrit et l'édite. Entre l'auteur et la Société s'interpose l'entreprise Caron, entreprise irresponsable qui ne rend des comptes à personne $\mathrm{e}^{56}$ ॥. Lors de cette même assemblée, Caron présenta un compte rendu très sévère des Euvres complètes de Saint-Just que Vellay venait de publier. Il critiquait l'ouvrage pour son absence de méthode, l'inclusion de documents peu importants, et le caractère incomplet des références aux sources. Il accusait Vellay d'avoir fait des emprunts directs au Recueil des actes du Comité de Salut public d'Aulard, sans citer son nom. Furieux, Mathiez s'opposa avec véhémence à ce qu'il considérait comme une attaque injuste contre son ami, le fondateur de la Société des études robespierristes, d'autant plus que cette attaque émanait d'un homme qu'il soupçonnait de malhonnêteté. Il croyait que c'était une tentative délibérée d'ébranler la Société de Vellay.

Vellay et Mathiez cherchèrent à riposter aux accusations de Caron, l'un par une lettre adressée à son critique, l'autre par un article publié dans les Annales révolutionnaires ${ }^{57}$. Aulard lui-même fut bientôt placé au banc des accusés, car il fut considéré comme responsable de l'antagonisme de Caron à l'égard de Vellay. On avait retranché de la lettre de Vellay adressée à la Société d'histoire moderne certains passages qui mettaient en question l'érudition d'Aulard. Caron lui-même appartenait à la Société de l'histoire de la Révolution. Les deux robespierristes dirigèrent alors leur feu contre Aulard. Mathiez publia une critique serrée de son ouvrage récemment paru, Taine historien de la Révolution française, dans les Annales révolutionnaires tandis que Vellay remettait en question la valeur scientifique de son Recueil des actes du Comité de Salut public. Le soupçonneux Mathiez et l'impétueux Vellay lançaient ainsi une offensive dirigée contre un savant respecté dans les milieux universitaires et très en vue dans les cercles républicains. Il devait en résulter un schisme entre Aulard et son ancien élève qui durerait plus de vingt ans. Mathiez croyait toujours que le vieil érudit était directement responsable de cette rupture. Dans sa lettre à Gottschalk, il s'exclama : «Aulard ne m'a pas pardonné la part que j'ai prise à la direction des Annales révolutionnaires! ${ }^{58}$. Désormais, Mathiez était ouvertement en guerre contre l'homme 
qui avait tant fait pour avancer sa carrière, mais qui était maintenant devenu son pire ennemi.

Si le premier numéro des Annales révolutionnaires ne menaçait pas Aulard en tant qu'érudit et en tant que personne, le deuxième l'assaillit directement. Mathiez avait sans aucun doute suivi la publication des articles d'Aulard sur Taine dans La Révolution française en 1906-1907. Maintenant, irrité par les attaques que Caron avait lancées contre la Société des études robespierristes, Mathiez consacra dix pages de sa revue à une critique détaillée de Taine historien de la Révolution française. Répétant ce qu'il avait déjà écrit en 1906, Mathiez semblait faire l'apologie de l'écrivain conservateur. «Taine loyalement a fait effort pour donner ses sources, souci que n'avaient guère ses prédécesseurs. De quelle sévérité n'aurait pas dû s'armer M. Aulard si au lieu de prendre Taine pour sujet de sa dissection, il avait choisi Thiers ou Michelet?", demanda-t-il. Puis il ajouta : «M. Aulard ne veut pas avouer que son livre est en un sens un livre de combat. Il se croit sûr d'être impartial. Il le dit seulement un peu trop ${ }^{59}$ ».

L'article de Mathiez consistait en une critique sévère de l'ouvrage d'Aulard. Celui-ci avait manqué aux exigences de la science historique, ce qu'il avait lui-même reproché à l'ouvrage de Taine, à savoir : la recherche de fautes mineures; l'application de critères stricts à sa méthodologie, qui n'était pas pire que celle des autres écrivains de l'époque ; la désapprobation d'omissions et d'erreurs chez Taine, bien qu'on en trouvât dans les ouvrages d'Aulard ; la condamnation du manque d'objectivité de Taine, alors qu'Aulard avait des préjugés certains contre Robespierre ; la mise en lumière d'erreurs dans les faits, bien qu'Aulard fût coutumier de ce genre de fautes; la réprobation des exagérations de Taine, alors qu'Aulard lui-même lançait des affirmations insoutenables. Mathiez alla jusqu'à déclarer que le vieil historien, en dépit des prétendues différences qui l'opposaient à Taine, n'était pas «si loin qu'on pourrait le croire des conceptions politiques de Taine »! Il ajouta : « Il est à peine moins antisocialiste que Taine [...]. Le grand crime de Robespierre, de Billaud et de Saint-Just, le crime qui fait leur pédantisme, c'est qu'ils ont exposé des vues quasi-socialistes ${ }^{60} »$.

Malgré toutes ces âpres critiques, Mathiez se montrait conciliant envers Aulard. Il trouvait le livre «si utile à tant d'égards par la masse énorme de faits qui s'y trouvent vérifiés ", et remarquait : "Désormais on ne pourra plus lire les Origines que l'erratum de M. Aulard à la main». Mais il concluait son compte rendu en déclarant : "Il ne faudrait pas que les lecteurs naïfs s'imaginent, en le lisant, qu'on est un grand historien quand on ne se trompe jamais dans les références des cotes d'archives ${ }^{61}$. Mathiez ne voulait probablement pas précipiter une rupture avec Aulard. Il s'était jusqu'alors montré prudent dans ses critiques à son égard. Toutefois, son compte rendu donna l'impression d'une déclaration d'indépendance intellectuelle. Mathiez entendait ne plus être traité en élève, mais comme l'égal de son ancien maître. Aulard fut sans doute surpris et fâché par l'article de Mathiez qui pourtant lui avait fréquemment exprimé sa reconnaissance pour les conseils reçus. L'éloge publié seulement trois ans auparavant dans la Revue des Charentes semblait être une preuve suffisante du respect que Mathiez lui avait porté. Dans son style voltairien, Aulard tenta d'en rire et de répondre à la critique par un article dans La Révolution française. Il remarqua en plaisantant que Mathiez, " par une aventure étrange, a un sosie ou plutôt un homonyme [...] qui écrit dans un nouveau périodique, les Annales révolutionnaires, et qui s'applique avec soin à prendre le contrepied des amitiés et de la méthode de notre excellent collaborateur et ami ». L'un de ces Mathiez «a écrit naguère aux dépens de ma modestie, mon éloge. 
L'autre M. Mathiez [...] prend le ton le moins amical pour rendre compte de mon livre sur Taine ». L'un était cordial, l'autre " pointilleux et querelleur ». Il fit rééditer l'article publié dans la Revue des Charentes, « quoi qu'il blesse ma modestie par l'exagération des éloges ", écrit-il, et " pour être agréable à $M$. Mathiez, dont le travail, si soigné, mérite une publicité plus ample que celle d'un périodique [...] local». Aulard parsema le texte de ses propres annotations, se jouant des louanges excessives que Mathiez lui avait adressées trois ans plus tôt. Il faisait allusion à certaines figures de style comme à une "fantaisie amicale", à "cette exagération", bien que ces expressions l'aient certainement flatté la première fois qu'il les lut ${ }^{62}$.

Si Aulard cherchait à embarrasser Mathiez, il se trompait totalement sur le compte de son ancien élève. Au lieu d'être humilié, Mathiez afficha un élan de colère qui ouvrit une campagne de vitupération contre le vieil érudit. Dans le numéro suivant des Annales révolutionnaires, Mathiez lança une attaque furieuse et personnelle sur l'œuvre et le personnage d'Aulard. Intitulée " Deux mots à M. Alphonse Aulard", elle donnait libre cours à tous ses griefs contre lui, dénonçant son érudition et l'accusant d'avoir provoqué la querelle qui séparait les deux historiens. Il justifia sa critique de l'étude d'Aulard sur Taine, confessa qu'il avait eu tort de déclarer que son Histoire politique de la Révolution française était un "monument d'immense érudition et de haute et sereine impartialité », et admit que l'article publié dans la Revue des Charentes avait été « fait sur commande ». Il déclara ensuite que « $\mathrm{M}$. Aulard sait bien qu'à aucun moment je n'ai accepté son œuvre en bloc, sans réserves, sans corrections ». Mathiez alla même jusqu'à dire que lorsqu'il défendait sa thèse de doctorat en 1904, ses opinions sur les cultes révolutionnaires différaient "radicalement" de celles d'Aulard. À cette époque, déclara-t-il, «j'ai touché du doigt, encore que discrètement, certaines imperfections des recueils de documents publiés sous [son] nom [...]». Les griefs d'Aulard contre son ancien élève résultaient cependant de l'adhésion de Mathiez à la Société des études robespierristes et de sa collaboration aux Annales révolutionnaires. "En vain », confessat-il, "ai-je caressé un instant l'espoir de continuer à La Révolution française une collaboration vieille de huit années. M. Aulard, en guise de remerciement, me signifie aujourd'hui qu'il ne souffre pas de partage. Qui n'est pas tout entier avec lui est contre lui. Ainsi sont les pontifes». Il prétendait qu'Aulard avait cherché dès le début à détruire la nouvelle société historique en grande partie parce qu'il ne pouvait pas supporter l'idée d'entreprendre "une œuvre de justice et de réparation nécessaires ». Bien qu'il regrettât la perte de l'amitié avec Aulard, Mathiez était incapable de tolérer la critique injuste de son travail. "Toutes les qualités qu'il voulait bien me reconnaître hier se transformeront demain en autant de défauts. C'est tout au plus si quelque disciple zélé ne m'accusera pas d'être vendu à la réaction ${ }^{63}$ ".

41 Une querelle entre deux historiens majeurs a rarement été jouée en public et exprimée en des termes si venimeux. Désormais, deux sociétés historiques, chacune avec sa propre revue, allaient exister côte à côte, les Annales révolutionnaires sous la direction de Mathiez, La Révolution française sous celle d'Aulard. Chacun cherchait à saper, sinon détruire, son rival. Toutefois, après sa première réaction contre l'assaut de son ancien élève, Aulard maintenait un silence méprisant envers lui. Ce refus de répondre irritait considérablement Mathiez. Dans son compte rendu de l'étude courte mais très critique d'Augustin Cochin, La Crise de l'histoire révolutionnaire, Taine et M. Aulard (1909), Mathiez conclut que « M. Cochin a rendu un grand service à la science historique en posant [...] dans cette brillante discussion des problèmes importants [...]. Il faut espérer que le débat qui ne fait que commencer ne s'arrêtera pas là ». Il ajouta : «M. Aulard n'a pas 
encore répondu à l'attaque, qui est déjà assez ancienne. Il n'est pas possible qu'il se taise plus longtemps. On finirait par croire qu'il n'a rien à répondre. Le silence du dédain n'est que la réponse de l'orgueil, rien de plus ${ }^{64} »$.

Si Mathiez jouait le rôle de Robespierre, son ami Charles Vellay jouait celui de SaintJust. Il chercha une revanche en rédigeant une critique détaillée du tome XVIII du Recueil des actes du Comité de Salut public qu'Aulard avait publié quelques mois plus tôt. Une note brève et anodine publiée dans le numéro de février de La Révolution française annonça sa parution et signala que dans l'introduction «le lecteur trouvera des indications sur le contenu du volume final de supplément [...] qui comprendra nombre de pièces, dont quelques-unes ont été omises par erreur et dont la plupart ont été retrouvées après coup, dans un travail de documentation extrêmement complexe ${ }^{65}$ ». En réalité, l'avertissement mis en tête du volume dressait une liste " des pièces omises, qui sont assez nombreuses ", qu'Aulard avait ignorées dans les dix-sept premiers volumes ${ }^{66}$. Vellay assaillit le Recueil à cause de son «absence presque complète de méthode » et déclara que " depuis vingt ans qu'il travaille à cette publication, [il] est resté aussi inexpérimenté que le premier jour ». Vellay considéra l'introduction du volume comme la preuve qu'Aulard lui-même avait reconnu les failles dans sa publication. Il ne pouvait plus cacher le "désordre» de sa méthodologie. Vellay lui reprocha aussi d'avoir omis des documents importants (1 400 selon Vellay), ainsi que d'avoir inclus des textes sans aucun rapport, comme par exemple la correspondance personnelle, d'avoir souvent résumé les textes au lieu de les citer in extenso, d'avoir reproduit des versions imprimées de documents plutôt que de consulter les originaux, etc. Vellay conclut d'une manière plutôt malveillante qu' " on mesurera le peu de valeur documentaire du Recueil des actes du Comité de Salut public, le peu de confiance que l'on doit avoir en lui [...]». Il prédit qu'Aulard, malgré toutes ses nombreuses erreurs, ne modifierait pas sa méthodologie et que les volumes suivants de la collection seraient non moins défectueux que ceux qui étaient déjà parus ${ }^{67}$.

Une telle violence verbale coûta aux Annales révolutionnaires un de ses fondateurs et contributeurs les plus importants, Arthur Chuquet. Prétextant qu'il avait besoin de temps pour diriger un nouveau périodique, les Feuilles d'histoire, il écrivit une lettre à Mathiez au printemps de 1909 annonçant son départ de la revue. Mais ce qui ennuya Mathiez fut la déclaration de Chuquet que «M. Aulard m'a prié de déclarer que je n'appartiens plus à la rédaction des Annales révolutionnaires». Il expliqua que «d'après lui, le public prétendrait que je suis pour quelque chose dans les critiques adressées à ses ouvrages. Vous savez qu'il n'en est rien. Je défère au désir de M. Aulard en vous priant d'imprimer cette déclaration». Mathiez prit note du départ de Chuquet avec peine, mais ajouta: "Quant à la démarche de M. Aulard, il serait trop cruel de la commenter ${ }^{68}$. La démission de Charles Vellay, l'organisateur en chef de la Société des études robespierristes et l'un des contributeurs principaux de la revue, fut beaucoup plus grave. Pour des raisons qu'il n'expliqua jamais complètement, le 19 novembre 1909, Vellay envoya inopinément une lettre au Comité directeur de la Société démissionnant de ses postes de secrétaire général, trésorier et membre de la commission des publications de la Société. Quelques jours plus tard, il démissionna également du Comité directeur. Pire encore, le 7 décembre, il écrivit aux membres de la Société pour leur faire savoir qu'il allait fonder une nouvelle revue et leur demanda de lui transférer leur allégeance des Annales révolutionnaires. Dans un rapport prononcé devant le Comité de la Société le 12 décembre, Mathiez déclara : « Il m'était très pénible de voir un collaborateur de la première heure se séparer d'une société qu'il a fondée 
[...] ». Mais il insista sur le fait que « quelque douloureuse que puisse être cette crise, je crois fermement que la société saura la traverser sans dommage, avec de l'union et de la bonne volonté $»^{69}$. Un an plus tard, dans un appel passionné aux membres de la Société, Mathiez déclara: "Nous ne pouvons [...] avoir pour amis que des hommes indépendants et désintéressés ». Puis, comme s'il présidait un club jacobin, il ajouta : « Notre œuvre, épurée des éléments équivoques, dure et prospère ${ }^{70}$.

Le Comité directeur conclut sa séance extraordinaire en renouvelant sa confiance à son président. Mathiez accepta la démission de Vellay et délégua son Comité des finances pour négocier avec lui afin de sécuriser les documents financiers et administratifs de la Société. Il désigna Hippo-lyte Buffenoir comme nouveau secrétaire général et le $\mathrm{D}^{\mathrm{r}}$. Blottière comme nouveau trésorier ${ }^{71}$. Lors d'une nouvelle réunion de la Société, tenue le 5 mai, Mathiez lut à l'assemblée une courte lettre assez virulente de Vellay, en date du 14 mars: «Je viens de prendre connaissance des pages qui me sont consacrées dans le numéro 9 des Annales révolutionnaires. J'aurais volontiers appelé l'attention de vos lecteurs sur les très nombreuses inexactitudes qui y sont contenues, si je n'avais acquis la preuve manifeste que l'un des membres de la commission qui dirige cette revue n'est qu'un plagiaire sans scrupules; et je croirais me discréditer en engageant la conversation avec une publication placée sous un tel contrôle ». Mathiez commenta : «Pas un fait, des insinuations injurieuses et perfides enveloppées dans un vague prudent ! $»^{72}$

45 Cela fut le dernier contact que Vellay eut avec la Société qu'il avait fondée à peine deux années auparavant. En 1910, il publia le premier numéro de sa propre publication, Revue historique de la Révolution française. Vellay tenta également de faire revivre une organisation du dix-neuvième siècle, la Société Robespierre, qui, écrivit-il, "groupe dans son sein tous ceux qui estiment que la personnalité et le rôle historique de Robespierre ont été défigurés [...] par les calomnies thermidoriennes et qu'il importe de replacer dans son vrai jour, par des études impartiales et précises, l'homme qui fut l'âme et le génie de la Révolution française $»^{73}$.

Après la Guerre de 14-18, Vellay partit pour Athènes où il poursuivit ses recherches sur la Grèce antique. Il céda le contrôle de sa revue à Otto Karmin, l'historien suisse qui avait été un membre fondateur de la Société des études robespierristes. La mort de celui-ci en 1920 provoqua l'interruption de la revue. Deux années plus tard, Gustave Laurent, robespierriste dévoué et maire adjoint de Reims, la fit revivre. Ancien contribu-teur aux Annales révolutionnaires, il avait été aussi membre de la Société. En 1923, les deux hommes se mirent d'accord pour fusionner leurs publications, fondant ainsi les Annales historiques de la Révolution française ${ }^{74}$. Mathiez se réjouit ainsi de la bonne nouvelle: "Toute la famille robes-pierriste est maintenant réunie au complet autour d'une revue unique, organe de notre Société $»^{75}$.

Mathiez et Laurent devinrent des co-directeurs de la nouvelle revue qui devait paraître six fois par an. Laurent s'occupait de sa publication à Reims, tandis que Mathiez l'éditait d'abord de Dijon, puis de Paris. De cette façon, ils partageaient le pouvoir mais risquaient moins de se quereller. Le départ de Vellay de la Société des études robespierristes se révéla comme un grand bénéfice pour Mathiez. En tant que président, il pouvait maintenant la dominer complètement et diriger les Annales révolutionnaires/Annales historiques de la Révolution française comme il le souhaitait. Il contrôla la Société tout en éditant et contribuant régulièrement à sa revue jusqu'à sa mort subite, survenue le 25 février 1932. 
Il est bien dommage que la Société des études robespierristes ait été créée à cause de rivalités personnelles. Le tempérament fougueux de Mathiez ainsi que son ambition provoquèrent une rupture permanente avec son ancien maître Aulard après la création de la nouvelle société. Pourtant, leur brouille représentait plus qu'une simple dispute entre des partisans de deux interprétations différentes de la Révolution ainsi qu'entre leur admiration pour des personnalités rivales, Danton et Robespierre. Au fond, elle marquait le fossé qui séparait l'école "officielle» des historiens soutiens de la Troisième République radicale et la nouvelle école à tendance socialiste qui critiquait la «république des camarades». Mathiez et Vellay pensaient retourner à une vieille tradition d'historiographie française en considérant Robespierre comme républicain honnête et même héroïque, en méprisant Danton, démagogique et vénal, admiré par Aulard et ses disciples. Dans cette lutte pour la vérité historique, où les personnalités et la politique étaient étroitement mêlées, chaque parti défendait sa propre vision de ce que la Troisième République, héritière de la Première, née de la Grande Révolution, devrait être. Finalement, Albert Mathiez et ses successeurs à la Société des études robespierristes triomphèrent. Un siècle plus tard, au moment du centenaire de leur création, la Société et sa revue continuent activement leur travail scientifique, et les Annales historiques de la Révolution française restent la seule revue internationale consacrée exclusivement à l'étude de la Révolution.

\section{ANNEXES}



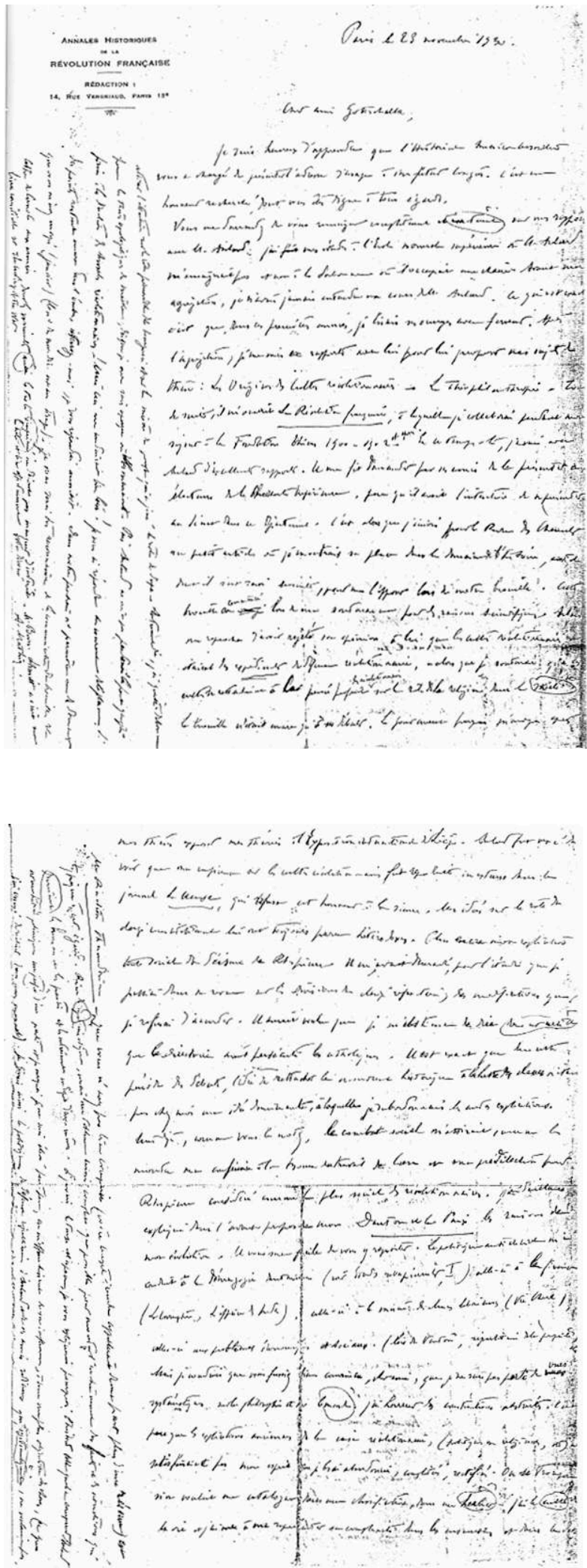


\section{NOTES}

1. Voir Claudine Wolikow, «Centenaire dans le bicentenaire: 1891-1991. Aulard et la transformation du cours en chaire d'histoire de la Révolution française à la Sorbonne ", Annales historiques de la Révolution française [ensuite AHRF], 1991, p. 431- 458.

2. Albert Mathiez, "François-Victor-Alphonse Aulard», Revue des Charentes, 31 mars 1905, p. 777-784.

3. En 1930, Mathiez adressa une lettre à son collègue américain, Louis Gottschalk, en réponse à une demande de « vous renseigner complètement et exactement sur mes rapports avec M. Aulard [...]». Datée du 23 novembre 1930, elle figure dans la correspondance de Gottschalk conservée aux archives de la Bibliothèque Regenstein à l'Université de Chicago. Elle fut publiée par Gottschalk dans les Annales historiques de la Révolution française, 1932, p. 218-220.

4. Ibid., p. 218.

5. AN, F17, dossier personnel Guillaume-Tiburce Castex.

6. Ibid. Sur le passage de Mathiez au lycée Ingres, voir Daniel Ligou, « Mathiez et Mon-tauban », AHRF, 1977, p. 32-42.

7. Revue historique, t. 67,1898 , p. 241-281 ; t. 68,1898 , p. 258-294 ; t. 69, 1899, p. 41-66.

8. Claude Perroud, La Révolution française, t. 37, 1899, p. 560-564.

9. Cet article, ainsi que plusieurs autres que Mathiez avait dédicacés à Aulard, se trouve dans la Bibliothèque Widener, à l'Université Harvard, sous la cote FR 1326.33.

10. Pendant qu'il étudiait à l'École normale supérieure, Mathiez, ami proche de Charles Péguy, avait adhéré au Parti socialiste. Voir : "Un premier état de la "Cité socialiste" : Lettre à Collier ", Feuillets de l'Amitié Charles Péguy, no 10 (mars 1950), p. 1-3. Tous deux partageaient une "turne" avec Georges Weulersse, le neveu de Georges Renard, alors rédacteur de La Revue socialiste. Renard devint ensuite un des premiers membres de la Société des études robespierristes fondée par Mathiez.

11. Gottschalk, « Une lettre », p. 218.

12. La Révolution française, t. 38, 1900, p. 44-72, 97-123.

13. Ibid., p. 289-333.

14. Ibid., t. 40, 1901, p. 295, 481-518.

15. La Grande encyclopédie, t. 30, Paris, H. Lamirault et Cie., 1901, p. 1192-1193.

16. Bulletin de la Société de l'histoire moderne, $\mathrm{n}^{\circ} 1$ (juillet 1901), p. 1-4.

17. Albert Troux, Un grand historien comtois: Albert Mathiez (1874-1932), Nancy, Georges Thomas, 1932, p. 14.

18. Gottschalk, « Une lettre », op. cit., p. 218-219.

19. «Le doctorat de M. A. Mathiez: Cultes révolutionnaires et Théophilanthropie ", La Révolution française, t. 46, 1904, p. 362.

20. La Théophilanthropie et le culte décadaire, 1796-1802. Essai sur l'histoire religieuse de la Révolution, Paris, F. Alcan, 1904, p. 10.

21. Albert Mathiez, « François-Victor-Alphonse Aulard », op. cit., p. 777-784.

22. Gottschalk, «Une lettre », op. cit., p. 219.

23. Albert Mathiez, «La question sociale pendant la Révolution française », La Révolution française, t. 48,1905, p. 393.

24. Alphonse Aulard, «Les origines historiques du socialisme français », Revue de Paris, 15 août 1899, p. 797- 829 ; repris dans ses Études et leçons, I V, Paris, F. Alcan, 1904, p. 20-68.

25. La Révolution française, t. 51, 1906, p. 566-567.

26. Le volume, se trouve dans la Bibliothèque Widener à l'Université Harvard sous la cote FR 1328.107. 
27. La Révolution française, t. 52, 1907, p. 97-131; t. 53, 1907, p. 139-167, 326-353, 385-410 ; t. 54, 1908, p. 97-130, 308-333. Ils allaient être réunis, joints à des documents additionnels, et publiés sous le titre Rome et le clergé français sous la Constitutante, Paris, A. Colin, 1911.

28. Alphonse Aulard, Taine historien de la Révolution française, Paris, A. Colin, 1907.

29. Ibid., p. V-VI. Pourtant, en mai 1906, alors qu'il présentait son cours sur Taine, il écrivait: «Quand Taine fit ses lourds volumes, ce fut pour écraser la démocratie, qu'il abhorrait, sous le poids de la prétendue érudition » (« Histoire de la Révolution : méthodes et résultats », La Revue du mois, 10 mai 1906, p. 539).

30. «Lundis révolutionnaires. La méthode de M. Taine ", La Justice, 29 décembre 1884.

31. "La statue de Taine", Action, 19 juillet 1903, article repris dans Polémique et histoire, Paris, Edouard Cornély, 1904, p. 39-43. Dans ce qui semble être une préparation à son cours et à son livre sur Taine, Aulard écrivit dans ce même article à propos des Origines de la France contemporaine: "[Taine] accepte, il utilise tout document qui lui semble confirmer sa thèse, justifier sa haine de la Révolution française [...]. [Il] accorde à ces sources, viles ou fausses, la même créance qu'aux sources authentiques et sérieuses ".

32. Pour le texte de sa conférence, voir: "Taine historien", Revue d'histoire moderne et contemporaine, t. 8, 1906-1907, p. 257-284.

33. Ibid., p. 283.

34. Les idées de Mathiez sur Taine reflétaient probablement l'influence de G. Monod, qui avait écrit des études impartiales mais critiques sur Taine. Voir Les maitres de l'histoire: Renan, Taine et Michelet, Paris, C. Lévy, 1894 ; et «H. Taine et la Révolution française », Revue bleue, 9 juillet 1904, p. 38-41.

35. Malheureusement, le biographe d'Aulard, son élève Georges Belloni, n'expliquait jamais les origines de la rupture. Il commente seulement: «Je n'essaierai point d'éclaircir les raisons qui l'en éloignèrent définitivement [...] Je dirai seulement qu'ayant fondé, en 1908, les Annales révolutionnaires, Albert Mathiez s'y montra fort malveillant envers Aulard. Étrange revirement! Aulard n'en revenait pas» (Georges Belloni, Aulard historien de la Révolution française, Paris, Presses universitaires de France, 1949, p. 39).

36. Danton et la paix, Paris, La Renaissance du livre, 1919, p. V.

37. Études et leçons, t. I, Paris, F. Alcan, 1893, p. 269. L'essai parut d'abord dans La Justice du 28 septembre 1885.

38. Danton et la paix, op. cit., p. V.

39. Par exemple: «Robespierre [...] et avec lui la nouvelle Commune de Paris formée de ses créatures [...] » (Albert Mathiez, «Catherine Théot», p. 498). La phrase en italiques ne figure pas dans ses Contributions à l'histoire religieuse de la Révolution française, Paris, F. Alcan, 1907.

40. Id., Contributions [...], op. cit., p. 124.

41. Revue critique d'histoire et de littérature, 1904, p. 490.

42. Jean Jaurès, Histoire socialiste de la Révolution française, Albert Mathiez (éd), Paris, Librairie de l'Humanité, 1922-1924, VIII, p. 178. Toutefois, selon Madeleine Rebérioux, Jaurès resta l'ami d'Aulard «au point de ne pas adhérer à la Société des études robespierristes » ( Histoire, historiens et dreyfusisme », Revue historique, t. 205, 1976, p. 432).

43. Voir, par exemple, l'article de Rouanet: " Robespierre à la Constituante en juillet 1789 ", Annales révolutionnaires [AR], 1918, p. 162-197, 289-317.

44. Ibid., 1923, p. 417-418.

45. Voir L'Éloquence parlementaire pendant la Révolution française. Les Orateurs de l'Assemblée constituante, Paris, Hachette, 1882.

46. Albert Mathiez, La Théophilanthropie [...], op. cit., p. $457 \mathrm{n}$.

47. AR, 1908, p. 515.

48. Gottschalk, « Une lettre », op. cit., p. 219-220. 
49. Lors de la première réunion officielle de la Société, le 29 novembre 1908, Charles Vellay, qui occupait provisoirement la fonction de secrétaire, nota qu'elle fut fondée le 18 juin 1907, mais ne fournit aucun autre détail, AR, 1909, p. 89 ; cf. Maurice Dommanget, «La Société et les Annales : cinquante ans d'histoire (1908-1958) », AHRF, 1958, n 152, p. 6-10.

50. Revue de Paris, 15 octobre 1906, p. 819-838.

51. Revue bleue, 10 août 1907, p. 186-187.

52. AR, 1909, p. 89-90.

53. Revue critique d'histoire et de la littérature, 9 décembre 1907.

54. La Revolution française, t. 52, 1907, p. 97-131; t. 53, 1907, p. 139-167, 326-353, 385-410 ; t. 54,1908, p. 97-130, 308-333. La publication de cette série fut interrompue par la rupture des deux historiens. Mathiez devait réunir ces articles dans son livre Rome et le clergé français sous la Constituante, Paris, Colin, 1911.

55. Bulletin de la Société d'histoire moderne, septième année, $n^{\circ} 5$ (mars 1908), p. 25-26.

56. Mathiez exposa ses nombreuses accusations contre Caron dans son article «À la Société d'histoire moderne », AR, 1908, p. 499-508.

57. Voir le Bulletin de la Société d'histoire moderne, septième année, $n^{\circ} 7$ (juin 1908), p. 37-38, pour la réponse de Vellay.

58. AHRF, 1932, p. 220.

59. $A R, 1908$, p. 349.

60. Ibid., p. 357.

61. Ibid.

62. La Révolution française, t. 54, 1908, p. 46-60, 81-83.

63. $A R, 1908$, p. 512-516.

64. Ibid., 1909, p. 607.

65. La Révolution française, t. 54, 1908, p. 186.

66. Voir le Recueil des actes du Comité de salut public, t. XVIII, Paris, Imprimerie nationale, 1908, p. I-XXXI. Il déclara, d'une manière assez optimiste, qu' "il n'y que quelques volumes à paraitre ». En fait, Aulard n'avait pas encore achevé la collection quand il mourut en 1928.

67. $A R, 1908$, p. 685-694.

68. Ibid., 1909, p. 155.

69. Ibid., 1910, p. 112.

70. « À nos amis », ibid., 1911, p. 283.

71. Ibid., 1910, p. 108-116.

72. Vellay révéla l'identité de cet individu dans son article « Essai d'une bibliographie de SaintJust ", Revue historique de la Révolution française, 1910, p. 427-435.

73. Voir: Charles Vellay (éd.), Observations sur Maximilien Robespierre par Philippe Buonarroti, Publications de la Société Robespierre, Chalon-sur-Saône, Imprimerie française et orientale E. Bertrand, 1912.

74. Lors d'une réunion du Comité directeur de la Société des études robespierristes tenue le 15 septembre 1923, Mathiez déclara que « tant que [la Revue historique de la Révolution française] était dirigée par un homme qui était animé contre notre œuvre d'intentions rien moins que bienveillantes, il ne pouvait entrer dans la pensée d'aucun de nous de tenter avec lui un rapprochement quelconque " $(A R, 1923$, p. 437). À propos de la fusion des deux revues, voir : Maurice Dommanget, «La Société et les Annales », AHRF, 1958, n 152, p. 17.

75. $A H R F, 1924$, p. 281. Le texte de l'accord unissant les deux revues fut publié dans les $A R, 1923$, p. 438-439, et de nouveau dans les AHRF, 1924, p. 284-285. 


\section{RÉSUMÉS}

En 1907, furent établies la Société des études robespierristes ainsi que sa revue, les Annales révolutionnaires, devenue en 1924 les Annales historiques de la Révolution française. Derrière cette création, se cache une rivalité entre deux historiens éminents, Alphonse Aulard et Albert Mathiez. Leurs points de vue historiques divergents et leurs fortes personnalités se heurtèrent, provoquant ainsi une querelle qui divisa les historiens de la Révolution en deux camps. Entre 1900 , date de leur première rencontre, et 1908, date de leur rupture définitive, les deux érudits semblaient être des amis proches qui partageaient un enthousiasme commun pour la Révolution. La formation d'une nouvelle société et d'une revue historique par Mathiez et d'autres historiens et des hommes politiques loyaux à Maximilien Robespierre, considéré comme le porte-parole de la démocratie populaire, menaçait l'«école officielle» favorable à l'orateur dynamique et éloquent Georges-Jacques Danton. Mathiez et ses successeurs à la Société des études robespierristes allaient triompher.

In 1907, the Société des études robespierristes as well as its review, the Annales révolutionnaires, which became in 1924 the Annales historiques de la Révolution française, was founded. Behind this creation was a hidden rivalry between two eminent historians, Alphonse Aulard and Albert Mathiez. Their divergent historical points of view and their strong personalities clashed, thus provoking a quarrel dividing historians of the Revolution into two camps. Between 1900, the date of their first meeting, and 1908, the date of their definitive rupture, the two scholars seem to have been close friends who shared a common enthusiasm for the Revolution. The formation of a new organization and a history journal by Mathiez and other historians and politicians loyal to Maximilien Robespierre, considered as the spokesman of popular democracy, threatened the " official school », itself favorable to the energetic and eloquent orator Georges-Jacques Danton. Mathiez and his successors in the Société des études robespierristes were going to triumph.

\section{INDEX}

Mots-clés : Aulard, Mathiez, Taine, Robespierre, Danton

\section{AUTEUR}

\section{JAMES FRIGUGLIETTI}

James Friguglietti, Montana State University-Billings, Billings, Montana 59101, États-Unis, jfriguglietti@msubillings.edu 